\title{
Total Deformity Angular Ratio as a Risk Factor for Com- plications after Posterior Vertebral Column Resection Surgery
}

\author{
Byoung Hun Lee, M.D., ${ }^{1}$ Seung-Jae Hyun, M.D., Ph.D., ${ }^{2}$ Sanghyun Han, M.D., ${ }^{3}$ Se-Il Jeon, M.D., ${ }^{4}$ Ki-Jeong Kim, M.D., Ph.D., ${ }^{2}$ \\ Tae-Ahn Jahng, M.D., Ph.D., ${ }^{2}$ Hyun-Jib Kim, M.D., Ph.D. ${ }^{2}$ \\ Department of Neurosurgery, Hallym University Hangang Sacred Heart Hospital, Seoul, Korea \\ Department of Neurosurgery, ${ }^{2}$ Spine Center, Seoul National University Bundang Hospital, Seoul National University College of Medicine, \\ Seongnam, Korea \\ Department of Neurosurgery, ${ }^{3}$ Chungnam National University Hospital, Chungnam National University College of Medicine, Daejeon, Korea \\ Department of Neurosurgery, ${ }^{4}$ Spine Center, Hyundai UVIS Hospital, Incheon, Korea
}

Objective : The aim of the present study was to identify whether the deformity angular ratio (DAR) influences the occurrence of complications after posterior vertebral column resection (PVCR) and to establish the DAR cut-off value.

Methods : Thirty-six consecutive patients undergoing PVCR from December 2010 to October 2016 were reviewed. The relationships between the total, sagittal, and coronal DAR and complications were assessed using receiver operator characteristics curves. The patients were divided into two groups according to a reference value based on the cut-off value of DAR. Demographic, surgical, radiological, and clinical outcomes were compared between the groups.

Results : There were no significant differences in the patient demographic and surgical data between the groups. The cut-off values for the total DAR (T-DAR) and the sagittal DAR (S-DAR) were 20.2 and 16.4 , respectively ( $p=0.018$ and 0.010 ). Both values were significantly associated with complications ( $p=0.016$ and 0.005$)$. In the higher T-DAR group, total complications $(12 \mathrm{vs.} 21, p=0.042)$ and late-onset complications ( 3 vs. 9, $p=0.036$ ) were significantly correlated with the T-DAR. The number of patients experiencing complications ( 9 vs. $11, p=0.029$ ) and the total number of complications ( 13 vs. $20, p=0.015$ ) were significantly correlated with the S-DAR. Worsening intraoperative neurophysiologic monitoring was more frequent in the higher T-DAR group (2 vs. 4) than in the higher S-DAR group (3 vs. 3). There was no difference in neurological deterioration between the groups after surgery.

Conclusion : Both the T-DAR and the S-DAR are risk factors for complications after PVCR. Those who had a T-DAR $>20.2$ or S-DAR $>16.4$ experienced a higher rate of complications after PVCR.

Key Words : Posterior · Vertebral column · Deformity · Risk factors · Complications.

\footnotetext{
- Received : June 2, 2018 •Revised : July 10, $2018 ・$ Accepted : July 21, 2018

- Address for reprints : Seung-Jae Hyun, M.D., Ph.D.

Department of Neurosurgery, Spine Center, Seoul National University Bundang Hospital, Seoul National University College of Medicine, 82 Gumi-ro 173beon-gil, Bundang-gu, Seongnam 13620, Korea

Tel : +82-31-787-7164, Fax : +82-31-787-4097, E-mail : hyunsj@snu.ac.kr
}

This is an Open Access article distributed under the terms of the Creative Commons Attribution Non-Commercial License (http://creativecommons.org/licenses/by-nc/4.0) which permits unrestricted non-commercial use, distribution, and reproduction in any medium, provided the original work is properly cited. 


\section{INTRODUCTION}

Vertebral column resection (VCR) is an effective surgical technique to correct severe spinal deformities ${ }^{7,12,17)}$. However, it is a challenging procedure because of its high complication rate and operative hardship ${ }^{1,2,4}$. To reduce the complications of conventional VCR, Suk et al. ${ }^{21)}$ described a posterior VCR (PVCR) technique. Nevertheless, there is still a risk of complications with $\mathrm{PVCR}^{3,14,18)}$. The incidence of complications after PVCR was reported to range from $40 \%$ to $67 \%{ }^{6,10,25)}$. Therefore, it is important for surgeons to recognize the risks associated with PVCR. In general, surgeons evaluate operative risk with reference to radiographs ${ }^{11}$. However, different curves, although similar in location and magnitude, can present different risks after the procedure ${ }^{16)}$. Previous studies have reported that a new scoring system involving the total deformity angular ratio (T-DAR) correlated to a neurologic complication during PVCR surgery. Wang and colleagues, stated that a greater DAR was associated with neurologic complication ${ }^{23}$. The DAR is the Cobb angle divided by the number of vertebrae involved in the curve (Fig. 1). The T-DAR is the sum of the coronal DAR (C-DAR) and the sagittal DAR (S-DAR) ${ }^{16,23)}$. Significant cut-off values for the T-DAR and the S-DAR were described as 25 and 15 , respectively ${ }^{23)}$. To the best of our knowledge, no previous studies have examined the correlation between the DAR and total complications after PVCR. It was

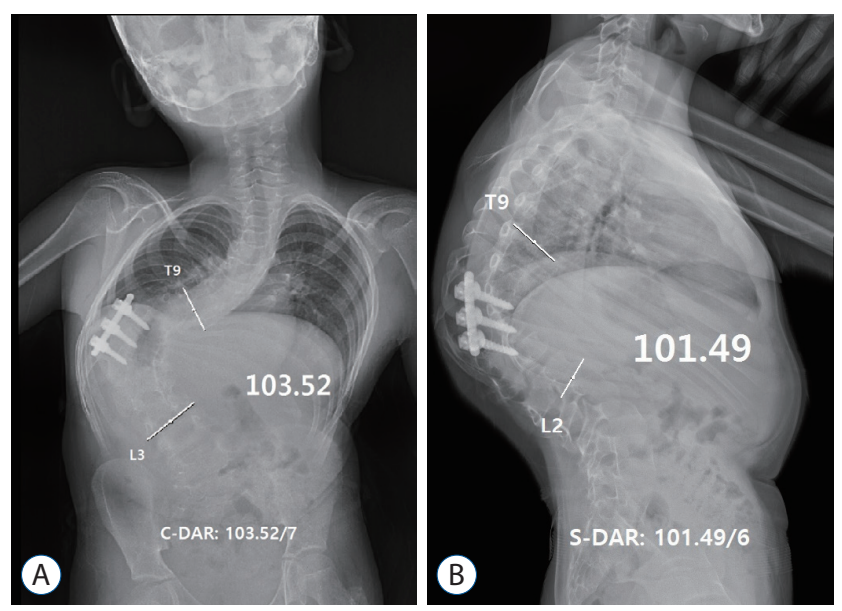

Fig. 1. The DAR. A case of $103.52^{\circ}$ scoliosis from T9 to $L 3$ (7 vertebrae) and $101.49^{\circ}$ kyphosis from T9 to L2 (6 vertebrae). A : C-DAR is 14.79 (103.52 divided by 7). B : S-DAR is 16.92 (101.49 divided by 6). T-DAR is 31.71 (T-DAR=C-DAR+S-DAR; $24.54=14.79+16.92)$. DAR : deformity angular ratio, C-DAR : coronal-DAR, S-DAR : sagittal-DAR, T-DAR : totalDAR. hypothesized that patients with a higher DAR prior to operation would have more complications after PVCR. The objective of the present study was to identify whether the DAR influences the overall complication risk after PVCR and to establish cut-off values.

\section{MATERIALS AND METHODS}

A total of 36 consecutive patients who had undergone PVCR from December 2010 to October 2016 were retrospectively reviewed. The study protocol was approved by the Institutional Review Board of Seoul National University Bundang Hospital (No. B-1803-456-101). At the time of enrollment, the inclusion criteria were : severe fixed deformity, sharp angular deformities, and three-dimensional multiplanar deformities. Patients with a spinal tumor, infection and combined anterior-posterior VCR surgery were excluded from the study. All patients received intravenous anesthesia and intraoperative neurophysiologic monitoring (IONM) was performed (Xltek protektor 32 IONM system; Natus 142 Medical Inc., Oakvile, Canada). The review was performed with clinical and radiographic sources. Demographic data, surgical time, estimated blood loss (EBL), length of hospital stay, revised Scoliosis Research Society-22 questionnaire (SRS-22r) scores, and complications were reviewed from the clinical evaluation. The radiologic evaluation involved the review of long-cassette $(14 \times 36$ inches) posterior-anterior and lateral standing plain radiographs pre-operatively, immediately after surgery, and from the most recent follow-up. The radiographic assessment included assessment of the sagittal vertical axis, the distance from the central sacral vertical line to a $\mathrm{C} 7$ plumb line, the coronal angle (proximal thoracic, main thoracic, and thoracolumbar curve), thoracic kyphosis, lumbar lordosis, and the kyphotic angle at the PVCR levels. The Cobb angle was measured on the preoperative and postoperative radiographs. The Cobb angle at the PVCR level was measured between the superior endplate of the first vertebra above the PVCR and the inferior endplate of the first vertebra below the PVCR.

The C-DAR was defined as the Cobb angle of the maximum scoliosis curve divided by the number of vertebral levels involved, and the S-DAR was the maximum kyphotic angle divided by the number of vertebral levels.. The sum of the coronal and sagittal scores was the T-DAR. The relationships be- 
tween the T-DAR and complications were estimated using receiver operator characteristics (ROC) curves and Pearson correlation analyses. The cut-off value was derived using the Euclidean method.

Euclidean method :

$$
\text { minimum } \sqrt{(1-S e n s i t i v i t y)^{2}+(1-S p e c i t i c i t y)^{2}}
$$

To ensure that cut-off value is the correct, the patients were divided into two groups according to the cut-off value. Comparative analysis between the groups was performed using the demographic, surgical, radiological and clinical outcomes. All complications were divided into three categories : intraoperative, perioperative ( $<2$ weeks after surgery), and late-onset postoperative ( $>2$ weeks after surgery). The number of patients with complications and the total number of complications were also identified. A comparative analysis of the two groups was used to determine whether there was a correlation.

An independent t-test was used to examine group differences for the continuous independent variables. A nonparametric Mann-Whitney U test was used for non-normal distributions. Statistical analysis was carried out using the Statistical Package for the Social Sciences version 20.0 (SPSS, Chicago, IL, USA). A $p$-value $<0.05$ was considered statistically significant.

\section{RESULTS}

Thirteen males and 23 females with a mean age of $58.7 \pm$ 22.8 years (range, $6-82$ years), were included in the study. The average follow-up duration was $24.8 \pm 14.1$ months (range, 9-76 months). The mean T-score for bone mineral densitometry and mean body mass index were $-2.6 \pm 1.3$ and $23.5 \pm 5.2$, respectively. Among the patients, sixteen cases exhibited a postfusion flat back deformity, eight cases had post-traumatic kyphosis, seven cases had post-tuberculosis kyphosis, and five cases had congenital kyphoscoliosis. Eighteen patients (50\%) had a history of prior spine surgery. The average fused vertebrae were 9.3 \pm 3.8 (range, 4-17). The number of PVCR segments was 48 levels (thoracic vertebrae, 22; lumbar vertebrae, 26). The Charlson Comorbidity Index which categorizes the comorbidities of patients was $2.4 \pm 1$.6. For the DAR, the values of the S-DAR $(10.8 \pm 3.6$ vs. $19.9 \pm 5.3, p<0.001)$ and the C-DAR (2.9 \pm 3.2 vs. $5.9 \pm 4.9, p=0.037)$ were significantly higher in the group with a T-DAR $\geq 20.2$ (Table 1 ). The operative character- istics and clinical outcomes are listed in Table 2. Surgical time, EBL, volume of transfused red blood cells, and length of hospital stay were increased in the group with a T-DAR of $\geq 20.2$. However, they were not significantly different between the two groups. Although there was no significant difference in the SRS-22r between the groups, patients with a higher TDAR ( $\geq 20.2)$ were more improved than the lower T-DAR patients. In the higher T-DAR group, the mean thoracic kyphosis correction angle $\left(11.0 \pm 6.7^{\circ}\right.$ vs. $\left.22.7 \pm 18.6^{\circ}, p=0.017\right)$, PVCR angle $\left(32.0 \pm 14.7^{\circ}\right.$ vs. $\left.46.7 \pm 21.2^{\circ}, p=0.021\right)$, and thoracolumbar scoliosis angle $\left(2.4 \pm 6.5^{\circ}\right.$ vs. $\left.9.0 \pm 10.2^{\circ}, p=0.031\right)$ were significantly greater than in the lower T-DAR group. The distance from the central sacral vertical line to the C7 plumb line $(-2.1 \pm$ 14.8 vs. $20.3 \pm 20.1, p=0.001)$ was more improved in the higher T-DAR group. Preoperatively, the angle at the PVCR site (17.8 $\pm 23.4^{\circ}$ vs. $\left.59.3 \pm 23.5^{\circ}, p<0.001\right)$, main thoracic scoliosis angle $\left(4.9 \pm 4.2^{\circ}\right.$ vs. $\left.10.8 \pm 8.6^{\circ}, p=0.013\right)$, and thoracolumbar scoliosis angle $\left(6.7 \pm 8.8\right.$ vs. $\left.15.8 \pm 16.6^{\circ}, p=0.046\right)$ were significantly greater in the higher T-DAR group (Table 3). For the S-DAR, the preoperative angle of the PVCR site $\left(22.4 \pm 23.5^{\circ}\right.$ vs. $64.0 \pm$ $\left.24.5^{\circ}, p<0.001\right)$ was significantly higher in the group with a higher S-DAR; however other factors were not significant.

The analysis of the complications is detailed in Table 4. Twenty of the 36 patients (55.6\%) experienced complications after surgery. In these 20 patients, the total number of complications was 33. Six patients showed changes in IONM, and two of these patients experienced transient neurological deterioration after the operation. Sixteen additional operations were performed in 11 patients. The rates of additional operation were not significant between the first and second cohorts (T-DAR, 33.3 vs. $55.6 \%, p=0.731$; S-DAR, 27.3 vs. $71.4 \%$, $p=0.053)$. The total number of complications was significantly higher in patients with a T-DAR value $\geq 20.2$ (21 vs. 12 , $p=0.042)$ and in patients with a higher S-DAR (20 vs. 13, $p=0.015$ ). The patients having complications ( 9 vs. $11, p=0.029$ ) had a significant correlation with S-DAR. The complications were divided into the three parts according to the time of onset. Late-onset complications ( $\geq 2$ weeks after surgery) were significantly higher in patients with a T-DAR $\geq 20.2$ (9 vs. 3 , $p=0.036$ ). However, the results for the intraoperative and perioperative complications were not significantly different between the groups. Both the T-DAR and the S-DAR were significantly related to complications $(p=0.018$ and 0.010 , respectively), however the C-DAR $(p=0.308)$ was not. The cut- 
Table 1. Demographic data

\begin{tabular}{|c|c|c|c|c|}
\hline & All patients $(n=36)$ & T-DAR $<20.2(n=18)$ & T-DAR $\geq 20.2(n=18)$ & $p$-value \\
\hline Age (years) & $58.7 \pm 22.8$ & $65.6 \pm 19.2$ & $51.8 \pm 24.4$ & 0.069 \\
\hline Male/female & $13 / 23$ & $5 / 13$ & $8 / 10$ & 0.378 \\
\hline Follow up duration (months) & $24.8 \pm 14.1$ & $26.2 \pm 13.3$ & $23.3 \pm 15.1$ & 0.554 \\
\hline BMD & $-2.6 \pm 1.3$ & $-2.4 \pm 1.1$ & $-2.7 \pm 1.4$ & 0.512 \\
\hline BMI & $23.5 \pm 5.2$ & $23.9 \pm 4.0$ & $23.1 \pm 6.2$ & 0.631 \\
\hline \multicolumn{5}{|l|}{ Etiology of deformity } \\
\hline Post-fusion flatback deformity & 16 & 11 & 5 & \\
\hline Post-traumatic kyphosis & 8 & 3 & 5 & \\
\hline Tuberculous kyphosis & 7 & 2 & 5 & \\
\hline Congenital kyphoscoliosis & 5 & 2 & 3 & \\
\hline Prior operation (\%) & $18(50.0)$ & $11(61.1)$ & $7(38.9)$ & 0.189 \\
\hline Number of fused segment & $9.3 \pm 3.8$ & $9.3 \pm 4.0$ & $9.2 \pm 3.8$ & 0.899 \\
\hline Number of PVCR segment & 48 & 18 & 30 & $0.041^{*}$ \\
\hline Thoracic & 22 & 7 & 15 & \\
\hline Lumbar & 26 & 11 & 15 & \\
\hline $\mathrm{CCl}$ & $2.4 \pm 1.6$ & $2.7 \pm 1.2$ & $2.1 \pm 1.9$ & 0.260 \\
\hline T-DAR (coronal+sagittal) & $19.8 \pm 7.8$ & $13.7 \pm 3.6$ & $25.8 \pm 5.7$ & $0.000^{*}$ \\
\hline Coronal-DAR & $4.3 \pm 4.4$ & $2.9 \pm 3.2$ & $5.9 \pm 4.9$ & $0.037^{*}$ \\
\hline Sagittal-DAR & $15.4 \pm 6.4$ & $10.8 \pm 3.6$ & $19.9 \pm 5.3$ & $0.000^{*}$ \\
\hline
\end{tabular}

Values are presented as mean \pm standard deviation or number (\%). ${ }^{*} p$ value $<0.05$. T-DAR : total deformity angular ratio, BMD : bone mineral density, $\mathrm{BMI}$ : body mass index, PVCR : posterior vertebral column resection, $\mathrm{CCl}$ : Charlson Comorbidity Index

Table 2. Operative characteristics and clinical outcomes

\begin{tabular}{|c|c|c|c|c|}
\hline & All patients $(n=36)$ & T-DAR <20.2 $(n=18)$ & T-DAR $\geq 20.2(n=18)$ & $p$-value \\
\hline \multicolumn{5}{|l|}{ Operative characteristics } \\
\hline Surgical time (minutes) & $411.5 \pm 165.3$ & $401.1 \pm 166.7$ & $422.2 \pm 167.9$ & 0.707 \\
\hline Estimated blood loss (mL) & $1163.3 \pm 1121.8$ & $1065.0 \pm 572.8$ & $1261.7 \pm 1497.5$ & 0.606 \\
\hline Volume of transfused RBC $(\mathrm{mL})$ & $1021.6 \pm 1095.2$ & $819.4 \pm 835.7$ & $1223.8 \pm 1297.9$ & 0.274 \\
\hline Length of hospital stay (days) & $17.4 \pm 10.8$ & $16.3 \pm 7.6$ & $18.6 \pm 13.4$ & 0.535 \\
\hline \multicolumn{5}{|l|}{ Clinical outcomes } \\
\hline \multicolumn{5}{|l|}{ SRS scores } \\
\hline Preoperative & $2.6 \pm 0.9$ & $2.7 \pm 0.9$ & $2.2 \pm 0.9$ & 0.256 \\
\hline Ultimate follow-up & $3.4 \pm 0.8$ & $3.3 \pm 0.9$ & $3.6 \pm 0.7$ & 0.180 \\
\hline
\end{tabular}

Values are presented as mean \pm standard deviation. T-DAR : total deformity angular ratio, RBC : red blood cell, SRS : Scoliosis Research Society

off values for the T-DAR and the S-DAR were 20.2 and 16.4, respectively. The T-DAR had a sensitivity of $70 \%$ and a specificity of $75 \%$. The S-DAR showed a sensitivity of $60 \%$ and specificity of $87.5 \%$. The area under the ROC curve for TDAR and S-DAR was significant at 73.1 and 75.3 , respectively ( $p=0.018$ and 0.010) (Fig. 2). Significant Pearson correlation coefficients were obtained between complications and T-DAR $(\mathrm{r}=0.399, p=0.016)$, and complications and S-DAR $(\mathrm{r}=0.458$, $p=0.005$ ) (Table 5). 
T-DAR and Complications after PVCR | Lee BH, et al.

Table 3. Radiographic data

\begin{tabular}{|c|c|c|c|c|}
\hline & All patients $(n=36)$ & T-DAR $<20.2(n=18)$ & T-DAR $\geq 20.2(n=18)$ & $p$-value \\
\hline Pelvic incidence $\left({ }^{\circ}\right)$ & $51.3 \pm 11.6$ & $52.8 \pm 11.9$ & $49.9 \pm 11.4$ & 0.453 \\
\hline \multicolumn{5}{|l|}{ Thoracic kyphosis $\left({ }^{\circ}\right)$} \\
\hline Preoperative & $25.9 \pm 28.0$ & $22.9 \pm 13.4$ & $29.0 \pm 37.3$ & 0.522 \\
\hline Postoperative & $28.5 \pm 16.4$ & $27.5 \pm 11.7$ & $29.9 \pm 20.6$ & 0.717 \\
\hline Ultimate follow-up & $32.0 \pm 19.5$ & $28.1 \pm 15.8$ & $35.2 \pm 22.7$ & 0.340 \\
\hline Correction & $16.9 \pm 15.0$ & $11.0 \pm 6.7$ & $22.7 \pm 18.6$ & $0.017^{*}$ \\
\hline Loss of correction & $-8.1 \pm 7.3$ & $-6.5 \pm 6.6$ & $-9.7 \pm 7.8$ & 0.186 \\
\hline \multicolumn{5}{|l|}{ Lumbar lordosis $\left({ }^{\circ}\right)$} \\
\hline Preoperative & $-21.5 \pm 38.2$ & $-21.4 \pm 28.1$ & $-21.6 \pm 47.1$ & 0.990 \\
\hline Postoperative & $-44.2 \pm 24.3$ & $-45.5 \pm 21.0$ & $-42.9 \pm 27.8$ & 0.749 \\
\hline Ultimate follow-up & $-37.7 \pm 27.8$ & $-41.8 \pm 23.9$ & $-33.5 \pm 31.3$ & 0.378 \\
\hline Correction & $31.9 \pm 27.1$ & $32.1 \pm 28.0$ & $31.7 \pm 27.0$ & 0.965 \\
\hline Loss of correction & $-8.3 \pm 8.8$ & $-7.1 \pm 8.1$ & $-9.4 \pm 9.4$ & 0.465 \\
\hline \multicolumn{5}{|c|}{ Sagittal verthotical axis (mm) } \\
\hline Preoperative & $97.1 \pm 87.9$ & $106.9 \pm 91.6$ & $87.4 \pm 85.5$ & 0.514 \\
\hline Postoperative & $22.7 \pm 45.7$ & $30.5 \pm 43.7$ & $14.9 \pm 47.4$ & 0.312 \\
\hline Ultimate follow-up & $46.2 \pm 57.0$ & $52.1 \pm 59.8$ & $40.4 \pm 55.1$ & 0.545 \\
\hline Correction & $75.7 \pm 92.6$ & $76.2 \pm 85.2$ & $75.2 \pm 101.9$ & 0.976 \\
\hline Loss of correction & $-19.3 \pm 43.2$ & $-18.8 \pm 37.4$ & $-19.8 \pm 49.5$ & 0.945 \\
\hline \multicolumn{5}{|c|}{ Angle at the PVCR site $\left(^{\circ}\right)$} \\
\hline Preoperative & $38.6 \pm 31.3$ & $17.8 \pm 23.4$ & $59.3 \pm 23.5$ & $0.000^{*}$ \\
\hline Postoperative & $-0.7 \pm 28.9$ & $-14.2 \pm 23.0$ & $12.7 \pm 28.4$ & $0.004^{*}$ \\
\hline Ultimate follow-up & $2.5 \pm 29.0$ & $-9.4 \pm 22.6$ & $14.3 \pm 30.4$ & $0.012^{*}$ \\
\hline Correction & $39.4 \pm 19.5$ & $32.0 \pm 14.7$ & $46.7 \pm 21.2$ & $0.021^{*}$ \\
\hline Loss of correction & $4.2 \pm 4.1$ & $-4.4 \pm 4.1$ & $-4.1 \pm 4.1$ & 0.797 \\
\hline \multicolumn{5}{|c|}{ Proximal thoracic scoliosis $\left({ }^{\circ}\right)$} \\
\hline Preoperative & $4.1 \pm 7.6$ & $2.2 \pm 2.0$ & $6.1 \pm 10.3$ & 0.099 \\
\hline Postoperative & $2.7 \pm 3.8$ & $1.4 \pm 1.9$ & $12.7 \pm 28.4$ & 0.124 \\
\hline Ultimate follow-up & $2.9 \pm 5.9$ & $1.4 \pm 3.0$ & $4.4 \pm 7.6$ & $0.031^{*}$ \\
\hline Correction & $1.4 \pm 5.1$ & $0.8 \pm 2.2$ & $2.0 \pm 7.0$ & 0.129 \\
\hline Loss of correction & $-0.3 \pm 3.9$ & $-0.1 \pm 2.4$ & $-0.5 \pm 5.0$ & 0.483 \\
\hline \multicolumn{5}{|c|}{ Main thoracic scoliosis $\left({ }^{\circ}\right)$} \\
\hline Preoperative & $7.8 \pm 7.3$ & $4.9 \pm 4.2$ & $10.8 \pm 8.6$ & $0.013^{*}$ \\
\hline Postoperative & $4.4 \pm 5.9$ & $3.2 \pm 3.6$ & $5.5 \pm 7.5$ & 0.261 \\
\hline Ultimate follow-up & $3.8 \pm 4.7$ & $1.6 \pm 4.1$ & $4.6 \pm 5.3$ & 0.301 \\
\hline Correction & $3.5 \pm 6.7$ & $1.6 \pm 4.7$ & $5.3 \pm 7.9$ & 0.099 \\
\hline Loss of correction & $-0.5 \pm 6.2$ & $-0.2 \pm 5.1$ & $-0.9 \pm 7.2$ & 0.746 \\
\hline \multicolumn{5}{|c|}{ Thoracolumbar scoliosis $\left({ }^{\circ}\right)$} \\
\hline Preoperative & $11.3 \pm 13.9$ & $6.7 \pm 8.8$ & $15.8 \pm 16.6$ & $0.046^{*}$ \\
\hline Postoperative & $5.8 \pm 8.8$ & $4.4 \pm 5.4$ & $7.3 \pm 11.2$ & 0.332 \\
\hline Ultimate follow-up & $5.6 \pm 8.9$ & $5.0 \pm 7.9$ & $6.2 \pm 10.0$ & 0.709 \\
\hline Correction & $5.7 \pm 9.1$ & $2.4 \pm 6.5$ & $9.0 \pm 10.2$ & $0.031^{*}$ \\
\hline Loss of correction & $-0.2 \pm 4.8$ & $-1.4 \pm 5.4$ & $-1.1 \pm 3.9$ & 0.139 \\
\hline \multicolumn{5}{|c|}{$\begin{array}{l}\text { Distance from the Central sacral vertical } \\
\text { line to } C 7 \text { plumb line }(\mathrm{mm})\end{array}$} \\
\hline Preoperative & $14.4 \pm 25.6$ & $2.7 \pm 18.1$ & $26.1 \pm 27.1$ & $0.004^{*}$ \\
\hline Postoperative & $5.3 \pm 19.0$ & $4.8 \pm 17.5$ & $5.8 \pm 20.8$ & 0.886 \\
\hline Ultimate follow-up & $7.1 \pm 26.6$ & $-2.2 \pm 22.2$ & $16.5 \pm 28.0$ & $0.033^{*}$ \\
\hline Correction & $9.1 \pm 20.8$ & $-2.1 \pm 14.8$ & $20.3 \pm 20.1$ & $0.001^{*}$ \\
\hline Loss of correction & $-2.0 \pm 30.3$ & $-6.4 \pm 28.3$ & $-10.3 \pm 30.7$ & 0.099 \\
\hline
\end{tabular}

Values are presented as mean \pm standard deviation. ${ }^{*} p$ value $<0.05$. T-DAR : total deformity angular ratio, PVCR : posterior vertebral column resection 
Table 4. Complications

\begin{tabular}{|c|c|c|c|c|c|c|c|}
\hline & \multirow{2}{*}{$\begin{array}{l}\text { All patients } \\
(n=36)\end{array}$} & \multicolumn{3}{|c|}{ T-DAR } & \multicolumn{3}{|c|}{ S-DAR } \\
\hline & & $<20.2(n=18)$ & $\geq 20.2(n=18)$ & $p$-value & $<16.4(n=22)$ & $\geq 16.4(n=14)$ & $p$-value \\
\hline Patients & $20(55.6)$ & $8(44.4)$ & $12(66.7)$ & 0.186 & $9(40.9)$ & $11(78.6)$ & $0.029^{*}$ \\
\hline \multicolumn{8}{|l|}{ Complications (case) } \\
\hline Intraoperative & 4 & 1 & 3 & 0.296 & 1 & 3 & 0.121 \\
\hline Perioperative (<2 weeks) & 17 & 8 & 9 & 0.898 & 7 & 10 & 0.071 \\
\hline Late-onset ( $\geq 2$ weeks) & 12 & 3 & 9 & $0.036^{*}$ & 5 & 7 & 0.095 \\
\hline Total & 33 & 12 & 21 & $0.042^{*}$ & 13 & 20 & $0.015^{*}$ \\
\hline IONM change & 6 & 2 & 4 & 0.378 & 3 & 3 & 0.683 \\
\hline Neurological deterioration & 2 & 1 & 1 & 1.000 & 1 & 1 & 0.114 \\
\hline Additional operation & 16 & $6(33.3)$ & $10(55.6)$ & 0.731 & $6(27.3)$ & $10(71.4)$ & 0.053 \\
\hline
\end{tabular}

Values are presented as number (\%). ${ }^{*} p$ value $<0.05$. T-DAR : total deformity angular ratio, S-DAR : sagittal deformity angular ratio, IONM : intraoperative neurophysiology monitoring

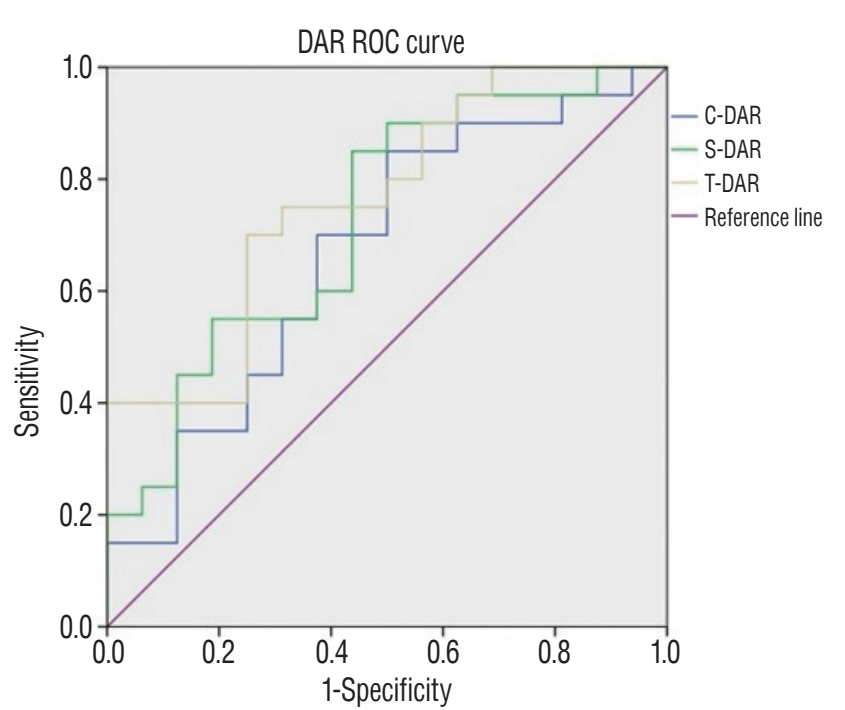

Fig. 2. The ROC curve for the DAR. The area under the ROC curve is 0.731 (T-DAR), 0.753 (S-DAR), and 0.600 (C-DAR). DAR : deformity angular ratio, ROC : receiver operator characteristics, C-DAR : coronal-DAR, S-DAR : sagittal-DAR, T-DAR : total-DAR.

\section{DISCUSSION}

PVCR is a surgically demanding technique with a high complication rate $(40-67 \%)$ after surgery ${ }^{6,10,25)}$. Neurologic complications are reported in $1.2-17.1 \%$ of patients ${ }^{5,15,20,26)}$. Because of these problems, surgeons should evaluate the risks and share the information with patients or their guardians before surgery. However, surgical risk can differ despite similarities in location and curve magnitude, because of different curve types $^{16)}$. Therefore, it is necessary to evaluate these curves to understand the risk involved. Previous studies have reported the relationship between the DAR and neurologic complications $^{16,23)}$. The evaluation method for overall complications should be considered, because PVCR had a higher overall complication rate ${ }^{6,10,25)}$. Total complication rate was as high as $55.6 \%$ in this study (neurologic deterioration, bleeding, dura tear, infection, complication of internal organs, screw loosening and malposition, adjacent segment fracture, proximal junctional kyphosis, etc.). The DAR method enables the characteristics of the angle of the curve to be determined. The DAR is the Cobb angle per vertebrae involved in the curve. It means that the DAR would be larger for a short, angulated deformity ${ }^{23)}$. It is accepted that a sharply angulated deformity is associated with more postoperative complications than a rounded deformity ${ }^{16)}$. In our study, it was confirmed that the deformity angle was significantly higher in the group with a larger DAR. Moreover, the correction angle was larger in the higher DAR group. This means that patients with a higher DAR have deformities that require more adjustments during surgery. When more correction of deformities is needed, the operation time may be longer and there may be more bleeding. Although there was no statistical significance in our study, operation time was longer (422.2 \pm 167.9 minutes vs. $401.1 \pm 166.7$ minutes) and there was more bleeding (1261.7 \pm $1497.5 \mathrm{~mL}$ vs. $1065 \pm 572.8 \mathrm{~mL}$ ) in the higher DAR group compared to the lower DAR group. Smith et al. ${ }^{19)}$ reported that excessive bleeding can cause ischemic change and neurologic complications. In addition to neurological disorders, postPVCR complications can appear throughout the body ${ }^{13)}$. 
Table 5. The relationship between DAR and complications

\begin{tabular}{lcccccc}
\hline & Sensitivity (\%) & Specificity (\%) & AUC & p-value & $\begin{array}{c}\text { Pearson correlation } \\
\text { coeffient (complication) }\end{array}$ & $\boldsymbol{p}$-value \\
\hline Total-DAR & 70 & 75 & 73.1 & $0.018^{*}$ & 0.399 & $0.016^{*}$ \\
Sagittal-DAR & 60 & 87.5 & 75.3 & $0.010^{*}$ & 0.458 & $0.005^{*}$ \\
Coronal-DAR & 60 & 62.5 & 60.0 & 0.308 & 0.033 & 0.847 \\
\hline
\end{tabular}

${ }^{*} p$ value $<0.05$. DAR : deformity angular ratio, AUC : the area under a receiver operator characteristics curve

Wang and colleagues described that PVCR is a reconstruction of the trunk of the body which contains the heart, great vessels, and respiratory organs. It is reported that respiratory-related complications are more frequent, because severe spinal deformity is often associated with respiratory function impairment $^{24)}$. We were able to identify that $12.1 \%$ of the total complications related to an internal organ $(5.6 \%$ were respiratory complications). Screw loosening or other instrument failures were also observed. These may be related to the increased risk when a lot of the anterior column is removed ${ }^{22}$. A large amount of the anterior column could be removed for calibration in a sharp angulated deformity with a higher T-DAR. In areas where large amounts of the anterior column have been removed, titanium mesh cages should be inserted to prevent nerve damage. A previous researcher ${ }^{22}$ reported that an anterior column defect $(>20 \mathrm{~mm})$ is a risk factor for instrument failure after PVCR. Fortunately, rod breakage did not occur in our patients, because we applied multi-rod constructs across the PVCR site. Hyun and colleagues ${ }^{8,9)}$ reported that the multi-rod system is an effective method that prevents implant failure after 3-column osteotomy. Although there was no statistical significance, reoperation was more frequent in the higher DAR group compared to the lower DAR group (TDAR, 10 vs. 6; S-DAR, 10 vs. 6). This seems to be related to the occurrence of more complications. In our study, neurologic deterioration did not correlate with the DAR. The reason for this is that the number of patients was relatively small. A significant correlation between the total number of complications and the DAR was observed in the present study. This suggests that the DAR may be a predictor of overall postoperative complications in addition to neurological outcomes ${ }^{23}$.

This study has several limitations due to the retrospective design. The number of patients in the study was small because of the stringent inclusion criteria. As a result, the objectivity of the cut-off value may be decreased. The patients were hetero- geneously selected, which can lead to selection bias that can affect result. The difference in the number of PVCR segment performed between groups may also be a bias that may affect the outcome. There could be a bias in each complication field because complications were evaluated as a whole without distinguishing between the types of complication. The number of complications is greater than the number of patients and there are bias that can affect the results. A history of previous surgeries in $50 \%$ of the total patients may have contributed to the PVCR complications. Nevertheless, the current study demonstrated that the DAR used for predicting neurological complications can correlate with the overall number of complications and the objective cut-off can be utilized for predicting the total complications.

\section{CONCLUSION}

Higher values for the T-DAR and the S-DAR are a risk factor for overall complications after PVCR. Those who had a TDAR of $\geq 20.2$ or a S-DAR of $\geq 16.4$ experienced a higher rate of complications after PVCR. These factors allow the surgeon to predict the likelihood of post-PVCR complications.

\section{CONFLICTS OF INTEREST}

No potential conflict of interest relevant to this article was reported.

\section{INFORMED CONSENT}

Informed consent was obtained from all individual participants included in this study. 


\section{References}

1. Boachie-Adjei $O$, Bradford DS : Vertebral column resection and arthrodesis for complex spinal deformities. J Spinal Disord 4 : 193-202, 1991

2. Bradford DS, Tribus CB : Vertebral column resection for the treatment of rigid coronal decompensation. Spine (Phila Pa 1976) 22 : 1590-1599, 1997

3. Demirkiran G, Dede O, Karadeniz E, Olgun D, Ay vaz M, Yazici M : Anterior and posterior vertebral column resection versus posterior-only technique: a comparison of clinical outcomes and complications in congenital kyphoscoliosis. Clin Spine Surg 30 : 285-290, 2016

4. Enercan M, Ozturk C, Kahraman S, Sarier M, Hamzaoglu A, Alanay A : Osteotomies/spinal column resections in adult deformity. Eur Spine J 22 Suppl 2 : S254-S264, 2013

5. Hamzaoglu A, Alanay A, Ozturk C, Sarier M, Karadereler S, Ganiyusufoglu K : Posterior vertebral column resection in severe spinal deformities: a total of 102 cases. Spine (Phila Pa 1976) 36 : E340-E344, 2011

6. Hassanzadeh H, Jain A, El Dafrawy MH, Ain MC, Mesfin A, Skolasky RL, et al. : Three-column osteotomies in the treatment of spinal deformity in adult patients 60 years old and older: outcome and complications. Spine (Phila Pa 1976) 38 : 726-731, 2013

7. Herbert JJ : Vertebral osteotomy; technique, indications and results. J Bone Joint Surg Am 30 : 680-689, 1948

8. Hyun SJ, Lee BH, Park JH, Kim KJ, Jahng TA, Kim HJ : Proximal junctional kyphosis and proximal junctional failure following adult spinal deformity surgery. Korean J Spine 14 : 126-132, 2017

9. Hyun SJ, Lenke LG, Kim YC, Koester LA, Blanke KM : Comparison of standard 2-rod constructs to multiple-rod constructs for fixation across 3-column spinal osteotomies. Spine (Phila Pa 1976) 39 : 1899-1904, 2014

10. Kim SS, Cho BC, Kim JH, Lim DJ, Park JY, Lee BJ, et al. : Complications of posterior vertebral resection for spinal deformity. Asian Spine J 6 : 257-265, 2012

11. Kim YJ, Hyun SJ, Cheh G, Cho SK, Rhim SC : Decision making algorithm for adult spinal deformity surgery. J Korean Neurosurg Soc 59 : 327333, 2016

12. Leatherman KD, Dickson RA : Two-stage corrective surgery for congenital deformities of the spine. J Bone Joint Surg Br 61-B : 324-328, 1979

13. Lee BH, Hyun SJ, Kim KJ, Jahng TA, Kim YJ, Kim HJ : Clinical and radiological outcomes of posterior vertebral column resection for severe spinal deformities. J Korean Neurosurg Soc 61 : 251-257, 2018
14. Lee BH, Hyun SJ, Park JH, Kim KJ : Single stage posterior approach for total resection of presacral giant schwannoma: a technical case report. Korean J Spine 14 : 89-92, 2017

15. Lenke LG, Newton PO, Sucato DJ, Shufflebarger HL, Emans JB, Sponseller PD, et al. : Complications after 147 consecutive vertebral column resections for severe pediatric spinal deformity: a multicenter analysis. Spine (Phila Pa 1976) 38 : 119-132, 2013

16. Lewis ND, Keshen SG, Lenke LG, Zywiel MG, Skaggs DL, Dear TE, et al. : The deformity angular ratio: does it correlate with high-risk cases for potential spinal cord monitoring alerts in pediatric 3-column thoracic spinal deformity corrective surgery? Spine (Phila Pa 1976) 40 : E879-E885, 2015

17. Makhni MC, Shillingford JN, Laratta JL, Hyun SJ, Kim YJ : Restoration of sagittal balance in spinal deformity surgery. J Korean Neurosurg Soc 61 : 167-179, 2018

18. Park YS, Hyun SJ, Kim KJ, Jahng TA : Multiple intradural disc herniations masquerading as intradural extramedullary tumors: a case report and review of the literature. Korean J Spine 13: 30, 2016

19. Smith JS, Wang VY, Ames CP : Vertebral column resection for rigid spinal deformity. Neurosurgery 63 (3 Suppl) : A177-A182, 2008

20. Suk SI, Chung ER, Kim JH, Kim SS, Lee JS, Choi WK : Posterior vertebral column resection for severe rigid scoliosis. Spine (Phila Pa 1976) 30 : 1682-1687, 2005

21. Suk SI, Kim JH, Kim WJ, Lee SM, Chung ER, Nah KH : Posterior vertebral column resection for severe spinal deformities. Spine (Phila Pa 1976) 27 : 2374-2382, 2002

22. Wang H, Guo J, Wang S, Yang Y, Zhang Y, Qiu G, et al. : Instrumentation failure after posterior vertebral column resection in adult spinal deformity. Spine (Phila Pa 1976) 42 : 471-478, 2017

23. Wang XB, Lenke LG, Thuet E, Blanke K, Koester LA, Roth $M$ : Deformity angular ratio describes the severity of spinal deformity and predicts the risk of neurologic deficit in posterior vertebral column resection surgery. Spine (Phila Pa 1976) 41 : 1447-1455, 2016

24. Wang Y, Xie J, Zhao Z, Zhang Y, Li T, Bi N, et al. : Perioperative major non-neurological complications in 105 patients undergoing posterior vertebral column resection procedures for severe rigid deformities. Spine (Phila Pa 1976) 40 : 1289-1296, 2015

25. Xie J, Wang Y, Zhao Z, Zhang Y, Si Y, Li T, et al. : Posterior vertebral column resection for correction of rigid spinal deformity curves greater than $100^{\circ}$. J Neurosurg Spine $17: 540-551,2012$

26. Zhang BB, Zhang T, Tao HR, Wu TL, Duan CG, Yang WZ, et al. : Neurological complications of thoracic posterior vertebral column resection for severe congenital spinal deformities. Eur Spine J 26 : 1871-1877, 2017 